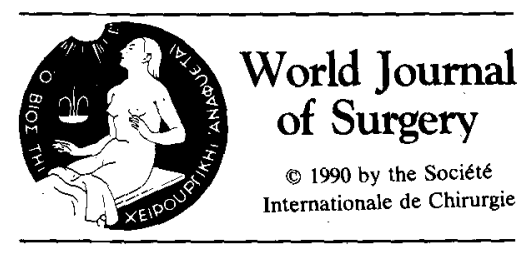

\title{
Surgery for Benign Insulinoma: An International Review
}

\author{
Matthias Rothmund, M.D., Lucio Angelini, M.D., L. Michael Brunt, M.D., John R. Farndon, M.D., \\ Glenn Geelhoed, M.D., Dimitrie Grama, M.D., Christian Herfarth, M.D., Edwin L. Kaplan, M.D., \\ Felix Largiader, M.D., Francesco Morino, M.D., Hans-Jürgen Peiper, M.D., Charles Proye, M.D., \\ Hans-Dietrich Röher, M.D., Klaus Rückert, M.D., Fritz Kümmerle, M.D., Norman W. Thompson, M.D., \\ and Jon A. van Heerden, M.D.
}

\begin{abstract}
Department of Surgery, University Hospital, Marburg, Federal Republic of Germany; Chair of Technology Applications in Surgery, 4th Department of Surgery, Rome, Italy; Department of Surgery, Washington University, St. Louis, Missouri, U.S.A.; Department of Surgery, The Royal Victoria Infirmary, Newcastle upon Tyne, Newcastle upon Tyne, England, United Kingdom; Department of Surgery, The George Washington University Medical Center, Washington, D.C., U.S.A.; Department of Surgery, University Hospital, Uppsala, Sweden; Department of Surgery, University Hospital, Heidelberg, Federal Republic of Germany; Department of Surgery, University of Chicago, Chicago, Illinois, U.S.A.; Department of Surgery, University Hospital, Zürich, Switzerland; Department of Surgery, University Hospital, Torino, Italy; Department of Surgery, University Hospital, Göttingen, Federal Republic of Germany; Department of Surgery, University Hospital, Lille, France; Department of Surgery, University Hospital, Düsseldorf, Federal Republic of Germany; Department of Surgery, University Hospital, Mainz, Federal Republic of Germany; Department of Surgery, University of Michigan Medical Center, Ann Arbor, Michigan, U.S.A.; and Department of Surgery, Mayo Clinic, Rochester, Minnesota, U.S.A.
\end{abstract}

In a multiinstitutional review, data on 396 patients with benign solitary or multiple insulinomas operated on in 15 centers were collected. In these 396 patients, 419 laparotomies (375 primary procedures and 44 reoperations) were performed. The rate of unnecessary laparotomies was $1.7 \%$. Complications occurred after 132 operations $(31.5 \%)$, requiring 27 reinterventions $(6.4 \%)$. Ten ( $2 \%$ ) patients died within 30 days of surgery. The success rate of first procedures in the centers was $94.9 \%$. After reoperation, all but $2(99.5 \%)$ of these patients were cured. The overall cure rate including those patients who had their primary operations elsewhere was $97.5 \%$.

The results of surgical treatment of benign and malignant insulinomas are published as reports from single institutions [1-6] or as multiinstitutional reviews scanning the cases published within a certain period of time [7-10] or collecting cases in a country by questionnaires $[11,12]$. Since the late 1970's when sophisticated and more reliable methods for diagnosis and localization of insulinomas became available, only a few institutions have published their data, usually based on a small series of patients [2-5]. Fifteen years ago, Stefanini and associates [10] published the last international review. Their data do not represent the results obtained today, e.g., a failure rate after primary operations of almost $25 \%$, an operative mortality of $6.7 \%$ after primary and of $18 \%$ after reoperations. This article describes current representative figures of the outcome of management of these tumors in a large number of patients.

Presented at the International Association of Endocrine Surgeons in Toronto, Ontario, Canada, September, 1989.

Reprint requests: Matthias Rothmund, M.D., Professor of Surgery, Department of Surgery, Philipps-University, Baldingerstraße, 3550 Marburg/Lahn, Federal Republic of Germany.

\section{Material and Methods}

A questionnaire was sent to 22 centers known for their interest in surgery of endocrine tumors of the pancreas. Fifteen centers were able to provide the appropriate data and to answer the questionnaire. Twenty-two questions asking for patient numbers, methods used in diagnosis and treatment, and results were included. Questions were not too detailed to avoid the temptation to estimate numbers in the answers. Some questions were asked to cross-check answers given before. Fourteen letters were sent to 9 institutions to ask specific questions which were not clearly answered in the original questionnaire. The data were then compiled and are presented below.

The centers were asked to answer the questionnaire only if the following prerequisites were fulfilled.

1. The data collection should begin after up-to-date methods for diagnosis of hyperinsulinism were available, i.e., radioimmunoassay for determination of insulin, C-peptide, or insulin-antibodies. For localization of the tumors, ultrasound, computed tomography scan, arteriography and selective venous sampling must have been available in the institutions. This was usually the case between 1977 and 1980 .

2. The surgeons in the centers had to be experienced in insulinoma surgery. A minimum of 2 operations for insulinoma per year were required during the time period screened.

3. The data collection starting between 1977 and 1980 had to be terminated by the end of 1987 and had to be complete enough to answer all of the questions in the questionnaire.

Data of 396 patients with benign solitary or multiple adenomas were collected. Data were also requested for malignant 
Table 1. Numbers of patients and operations reported in the review.

\begin{tabular}{lr}
\hline No. of patients & 396 \\
Minimum per institution & 14 \\
Maximum per institution & 68 \\
No. of operations & 419 \\
Primary operations & 375 \\
Reoperations (in 35 patients) & 44 \\
1st operation in own institution & 19 \\
1st operation elsewhere & 16 \\
Factitious hypoglycemia & 7 \\
\hline
\end{tabular}

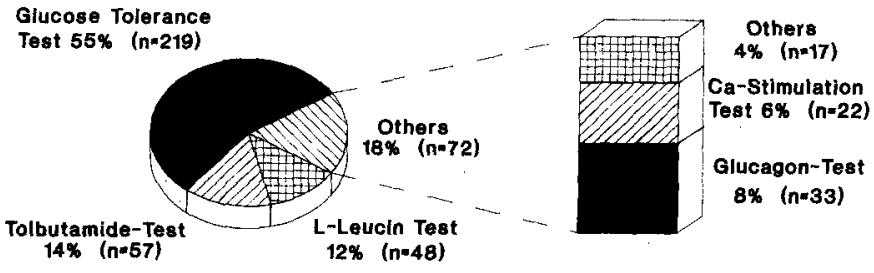

Fig. 1. Provocative tests used by the authors in addition to the fasting test.

Table 2. Methods used for preoperative localization of insulinomas.

\begin{tabular}{|c|c|c|c|c|c|}
\hline & Ultrasonography & $\begin{array}{l}\text { Computed } \\
\text { tomography }\end{array}$ & Arteriography & $\begin{array}{l}\text { Percutaneous } \\
\text { transhepatic } \\
\text { portography }\end{array}$ & Other \\
\hline No. of patients investigated & 142 & 246 & 305 & 80 & 26 \\
\hline Correct localization & 60 & 82 & 188 & 71 & 15 \\
\hline Accuracy $(\%)$ & 39.2 & 33.3 & 61.6 & 88.7 & 57.6 \\
\hline
\end{tabular}

beta-cell tumors ( 84 cases) and for islet-cell hyperplasia (30 cases) observed in the same period. These cases were not of specific interest in the study and were, therefore, excluded from the subsequent analysis. The minimum number of patients with benign insulinomas reported per institution was 14 and the maximum was 68 .

\section{Results}

In these 396 patients, a total of 419 operations were carried out including 375 primary operations and 44 reoperations. Reoperations were performed in 35 patients: 1 reoperation in all cases, a second in 7 cases, and more than 2 reoperations were necessary in 2 cases. In 19 of these patients, the primary procedure was performed in the centers and in 16 patients it was performed elsewhere. In the same period of time, 7 patients had an exploratory laparotomy with the intent of excising an insulinoma, but these patients had factitious hypoglycemia. Adding these 7 patients to the 396 patients with proven hyperinsulinism, one calculates a rate of $1.7 \%$ unnecessary laparotomies because of misdiagnosis (Table 1).

\section{Diagnosis}

In all of the patients, the fasting test simultaneously measuring blood glucose and immunoreactive insulin levels for up to 72 hours was used. In most institutions, C-peptide levels were measured and some used the determination of insulin antibodies to exclude factitious hypoglycemia caused by insulin injection. A series of other provocative tests was performed. These tests and their absolute and relative incidence in the 396 patients is described in Fig. 1. Comments made in the questionnaire indicate that the use of provocative tests in addition to the fasting test decreased during the time period observed.

\section{Localization}

In the majority of cases, well-known imaging procedures such as ultrasound, computed tomography scan, arteriography, and percutaneous transhepatic selective venous sampling were used. In some patients, other methods such as barium studies, scintiscanning, and, more recently, magnetic resonance imaging were performed. The absolute numbers of investigations in these patients and the number of correct localizations and the relative accuracy of the methods are given in Table 2 .

\section{Operation}

For intraoperative localization, the procedures summarized in Table 3 were performed. The test most frequently applied was intraoperative glucose monitoring. It indicated whether the tumors demonstrated by preoperative procedures or palpated during exploration were completely excised. Few centers utilized intraoperative ultrasound, but this method was becoming more popular.

In the questionnaire, the site of solitary adenomas excised was asked. Fig. 2 shows that the tumors were equally distributed throughout the pancreas and about $1 \%$ were ectopic. In 42 patients $(10.6 \%)$, multiple insulinomas were found. The exact number and the relative incidence is given in Fig. 3. Most of the 29 cases $(7.3 \%)$ with the MEN I syndrome were found among this group with multiple tumors.

The surgical procedure used to remove the tumor depended on its site. Fig. 4 illustrates the procedures performed. Most tumors situated in the head of the pancreas were removed by enucleation. One in 10 patients underwent a Whipple procedure at first surgery to remove an insulinoma from the head of the pancreas. The standard procedure for tumors in the body and/or tail was distal pancreatectomy. In a little more than one-third of the patients, these tumors were removed by enucleation.

In reoperations, a Whipple procedure was used as often as an enucleation for resection of insulinomas located in the head of the pancreas. Reoperations resulted in 5 patients as total pancreatectomies because, in previous surgery, a part of the gland had already been removed (Fig. 5).

\section{Complications and Mortality}

Complications occurred following $132(31.5 \%)$ of the 419 operations leading to reexplorations after 27 operations $(6.4 \%)$. The 
Table 3. Methods used for localization during or for completeness of excision.

\begin{tabular}{lrr}
\hline Method & $\mathrm{n}$ & \multicolumn{1}{c}{$\%$} \\
\hline Glucose monitoring & 108 & 25.8 \\
Ultrasound & 72 & 17.2 \\
Aspiration biopsy + cytology & 6 & 1.4 \\
Quick insulin radioimmunoassay & 3 & 0.7 \\
Others (e.g., frozen section biopsy) & 8 & 1.9 \\
\hline
\end{tabular}

Body $(n-103)$ $30 \%$

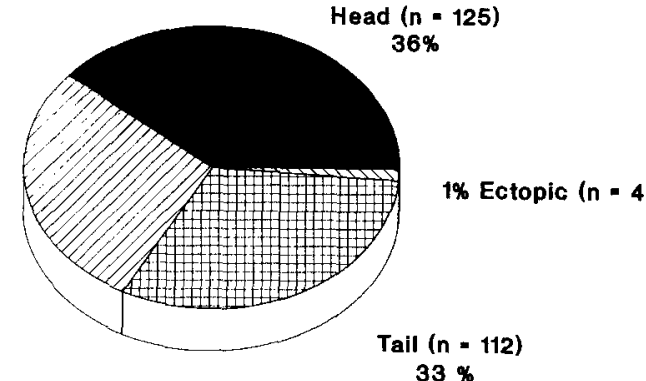

$33 \%$
Fig. 2. Anatomic distribution of solitary adenomas.

\section{2 patients(10.6\%)}

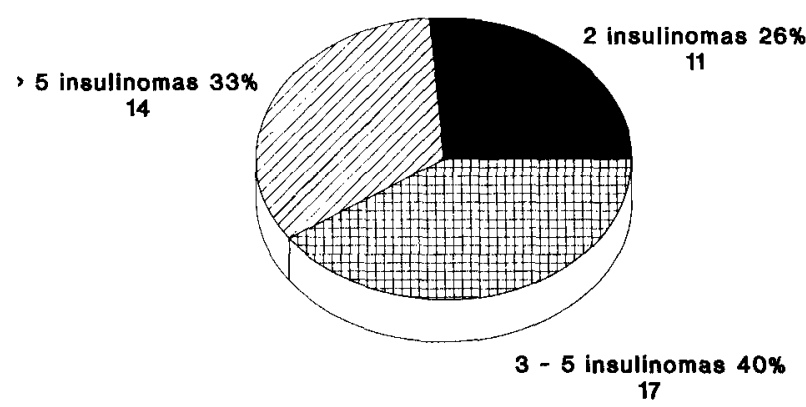

Fig. 3. Absolute number and relative incidence of multiple insulinomas found in $\mathbf{4 2}$ patients.

complications are detailed in Fig. 6. Pancreatic fistulas and pancreatitis were the most common complication followed by sepsis, bleeding, and pneumonia. The 30-day mortality in the 396 patients reported was $2 \%$ ( 8 patients). If one relates the mortality to procedures, 6 patients $(1.6 \%)$ died after the 375 primary operations and $2(5.7 \%)$ of 35 patients died following one or more reoperations (Table 4).

\section{Outcome}

The success rate of first operations performed at the centers was $94.9 \%$, i.e., hyperinsulinism persisted in $5.1 \%$ of the patients. Failure of the operation was assumed if one or more of the following criteria were observed:

1. No endocrine tissue removed (histology)

2. Persistent hypoglycemia during fasting test

\section{Localization vs. Procedures}

Primary Operations (n)

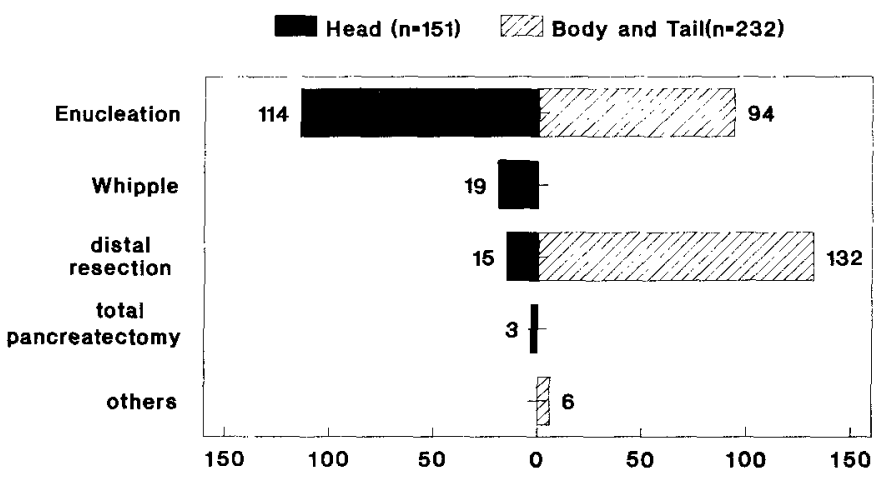

Fig. 4. Operations performed to remove the insulinomas depending on the site of the tumors during primary operations.

\section{Localization vs. Procedures} Reoperations ( $n$ )

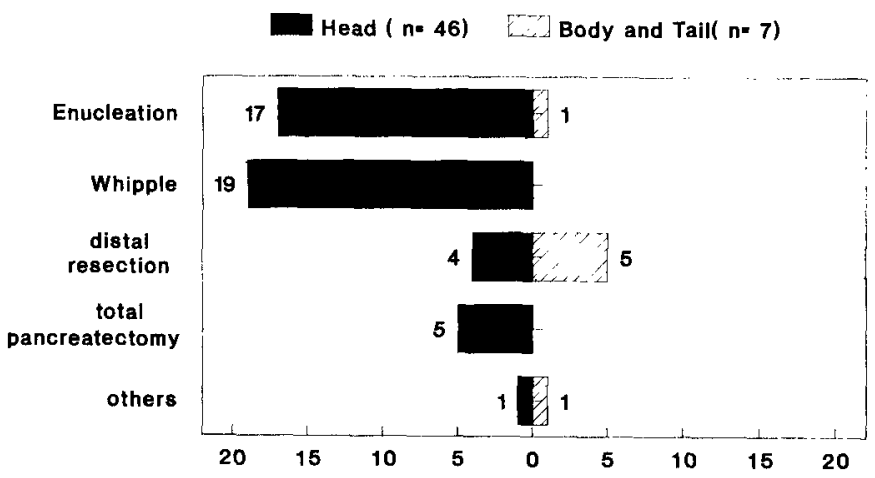

Fig. 5. Operations performed to remove the insulinomas during reoperations.

3. Abnormal glucose tolerance test or elevated plasma insulin levels

Hyperinsulinism persisted in 10 of the 35 patients who had a total of 44 reoperations, meaning the failure rate in reoperations was $28.6 \%$ (Table 5). If one looks at the whole group of patients reported by the 15 centers, surgery was not successful at all in $10(2.5 \%)$ of 396 patients after a total of 419 operations. If the primary operation was performed at one of the centers $(n=$ $375)$, only 2 patients $(0.5 \%)$ could not be cured by surgery. This was the case in 8 patients where the first operation was done elsewhere. Six of the 10 patients, treated without success, had multiple tumors (Table 6).

\section{Discussion}

Surgeons have been interested in the outcome of management of benign insulinomas since the first collective review of 8 


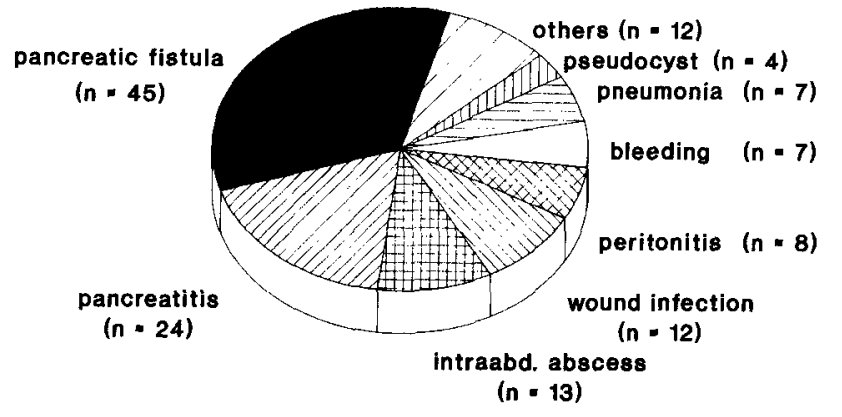

Fig. 6. Postoperative complications after 132 (31.5\%) of 419 operations.

Table 4. Postoperative complications and mortality.

\begin{tabular}{lrr}
\hline & $\mathrm{n}$ & $\%$ \\
\hline Complications & 132 & 31.5 \\
Reinterventions & 27 & 6.4 \\
30-day mortality $(\mathrm{n}=396)$ & 8 & 2.0 \\
1st procedures $(\mathrm{n}=375)$ & 6 & 1.6 \\
Reoperations $(\mathrm{n}=35)$ & 2 & 5.7 \\
\hline
\end{tabular}

patients published by Whipple and Frantz in 1935 [13]. Four further reviews in the English literature were published covering a fixed period of time [7-10]. Two others used questionnaires $[11,12]$ but canvassed a large number of surgeons with varying degrees of experience and long time periods with changing methods of diagnosis and treatment.

This study attempted to limit these variables by questioning surgeons with a known experience and practice in pancreatic endocrine tumors. The time period was restricted to limit variability in methods of diagnosis and localization. The questionnaire incorporated questions to allow internal control or audit of accuracy of response.

This report documents better results than the previous multiinstitutional reviews [7-12]. Improved outcome is mainly due to more reliable diagnostic procedures. The fasting test, proving Whipple's triad, became more sensitive after plasma insulin could be measured. In this study, only 7 patients $(1.7 \%)$ had exploratory laparotomies and no organic hyperinsulinism. Cpeptide and/or insulin antibodies were not determined in all patients. The use of one or both of these tests might have reduced the number of unnecessary laparotomies. There are no comparable figures in the literature and although the rate of $1.7 \%$ appears to be low, it shows that diagnostic errors can still occur.

Many authors used provocative tests, glucose tolerance test, tolbutamide test, L-leucine tests, and others. In the first author's opinion, a carefully performed fasting test is sufficient to make a reliable diagnosis in most patients. There is a place for provocative tests if the fasting test does not produce hypoglycemia in the face of strong clinical evidence [2]. In this situation, the use of the tolbutamide test or a short calcium stimulation test might be more useful than the glucose tolerance test.

Selective arteriography was the most often utilized localization procedure but did not show as good results as described by
Table 5. Failure rates in primary operations and in reoperations performed at the centers.

\begin{tabular}{llr} 
& $\mathrm{n}$ & \multicolumn{1}{c}{$\%$} \\
\hline No. of 1st operations (centers) & 375 & 100.0 \\
Failed operations & 19 & 5.1 \\
No. of cases (44 reoperations) & 35 & 100.0 \\
Failed operations & 10 & 28.6 \\
\hline
\end{tabular}

Table 6. Failure rates of the whole group of patients collected (the percentage of failed operations in cases where primary operations were performed elsewhere cannot be given because the total number of operations is unknown).

\begin{tabular}{lrr}
\hline & $\mathrm{n}$ & \multicolumn{1}{c}{$\%$} \\
\hline Total no. of patients & 396 & 100.0 \\
Not cured after surgery (419 operations) & 10 & 2.5 \\
Primary operation at center & 2 & 0.5 \\
Primary operation elsewhere & 8 & \\
Multiple tumors: 6 of 10 & & \\
\hline
\end{tabular}

van Heerden and associates [2]. The best results were achieved by percutaneous transhepatic portography (PTP) and venous sampling for insulin assay. The accuracy was nearly $90 \%$. This number is not comparable with the results of the other methods; it was based on a rather small sample of patients and the method only indicates in which area of the pancreas the tumor is situated, i.e., an exact circumscribed localization is not given.

Similar figures for accuracy of preoperative localization were published by Boissel and Proye [12]. Daggett and colleagues [14] showed that these procedures were not as good as a meticulous surgical exploration. The advent of intraoperative ultrasound might make preoperative localization procedures less important and preoperative ultrasound (which was used in this survey less often than computed tomography scan and arteriography) might become the only worthwhile preoperative method [15].

During surgery, most surgeons do not use any localization method except a meticulous surgical exploration and palpation of the gland. Glucose monitoring, described in 1951 [16], cannot be called a localization procedure, but it informs the surgeon with a more than $90 \%$ accuracy whether all insulinoma tissue had been resected $[1,2,5]$. Ultrasound during surgery with surgical exploration allows insulinomas to be localized in 90$100 \%$ of patients $[15,17]$. The method is available only in a few centers since 1983 . It, therefore, was used in less than $20 \%$ of the operations in this study.

The tumors found during surgery were equally distributed throughout the pancreas. This is in accordance with the literature as well as the fact that about $10 \%$ of the patients had multiple insulinomas.

When operative procedures are related to the site of the tumors, it is surprising that $12.6 \%$ of the insulinomas located in the head of the pancreas were removed by a Whipple procedure during primary operations. Similar figures have not been published in the literature. In a collective series of 207 benign insulinomas operated on in the Federal Republic of Germany, the insulinomas were removed by this method during first procedures [11] in 2 cases (1\%). In a French survey, an 
insulinoma was removed by a Whipple procedure during primary operation [12] in 20 (5.5\%) of 366 patients. Among 72 patients, published from the Mayo Clinic, only 2 had Whipple procedures [2]. Most authors agree that the Whipple procedure is too radical a therapy for a benign insulinoma of the head of the pancreas $[3,18]$, In this multiinstitutional review, enucleation was the procedure of choice for insulinomas in the head of the pancreas. The same was true for distal resection or enucleation for tumors in the body and tail of the pancreas. The Whipple procedure was the most commonly used procedure during reoperations to remove tumors from the head of the gland and enucleation was the second most common procedure.

The complication rate of $31.5 \%$ reported in this review is rather high. In earlier publications, the complication rate was $15 \%[2,12], 20 \%[1,10]$ or $28 \%$ [5]. Complications of pancreatic fistula and pancreatitis were most often encountered followed by septic complications and bleeding.

In contrast to the high morbidity, mortality was low, Only 8 $(2 \%)$ of 369 patients died up to 30 days after surgery and reoperations were more hazardous than primary procedures. The comparison to the previously published literature shows that, obviously, postoperative complications can, nowadays, be managed better than before. Few centers report zero mortality $[2,19]$, but surveys undertaken in France and the Federal Republic of Germany showed a mortality rate of $6 \%$ and $6.2 \%$, respectively $[11,12]$. Harrison and associates [1] had a rather low mortality of $2.8 \%$. In their major review, Stefanini and colleagues [10] described a mortality rate of $11 \%$ and, as in our report, the mortality was higher after reoperations than after first operations (18\% versus $7 \%$ ). Galbut and Markowitz [5] report a similar mortality rate of $12 \%$ among their patients.

Successful surgical treatment is defined as absence of hypoglycemia, histological proof of endocrine tissue removed from the patient, and a normal glucose tolerance test. Based on that definition, the success rate of first operations performed at the authors' institutions was $94.9 \%$. Including reoperations, all but $2(0.5 \%)$ of the authors' 375 patients were cured. If one adds the patients who had their primary operation elsewhere, $10(2.5 \%)$ of 396 patients were not cured. That means the overall success rate was $99.5 \%$ or $97.5 \%$, respectively. Data demonstrating such a high rate of successful surgical management have not been published previously in a multiinstitutional review. Stefanini and associates [10] reported failed surgery after primary operations in $23.7 \%$ and no tumor was found in $7 \%$ after multiple reoperations. Sixteen percent of the cases had persistent or recurrent hypoglycemia. In the French survey published in 1985 [12], only $87 \%$ of the patients were cured primarily or including reoperations.

Even if the authors demonstrate convincing results in terms of cure rate and mortality, the management of benign solitary or multiple insulinomas can be improved. Facticious hypoglycemia must be excluded by routine use of C-peptide and/or insulin antibody determination and by measuring serum levels of sulfonyl urea in suspicious patients. Localization of tumors can be improved by increasing use of intraoperative ultrasound and by increasing versatility of surgeons in this technique. More careful handling of the pancreas and meticulous resection techniques may reduce complications and mortality.

\section{Résumé}

Compilant les dossiers de 15 établissements internationaux, nous avons colligé les données concernant 396 patients présentant un insulinome bénin unique ou multiple, opérés. Chez ces 396 patients, 419 laparotomies (375 interventions de première intention et 44 reprises) ont été effectuées. Le taux de laparotomie inutile était de $1.7 \%$. Des complications sont intervenues à la suite de 132 opérations (31.5\%), nécessitant 27 réinterventions (6.4\%). Dix (2\%) patients sont morts dans les trente jours après l'acte chirurgical. Le taux de succès des interventions de première intention dans les centres de l'étude était de $94.9 \%$. Après réinterventions, tous les patients sauf $2(99.5 \%)$ ont été guéris. Le taux global de guérison, y compris les patients ayant été opérés une première fois ailleurs, était de $97.5 \%$.

\section{Resumen}

En una revisión multiinstitucional se recolectaron los datos sobre 396 pacientes con insulinomas benignos solitarios o múltiples operados en 15 centros. En estos 396 pacientes se efectuaron 419 laparotomías ( 375 procedimientos primarios y 44 reoperaciones). Se registró una tasa de laparotomías innecesarias de 1.7\%; se presentaron complicaciones después de 132 operaciones $(31.5 \%)$, las cuales requirieron 27 reintervenciones (6.4\%). Diez ( $2 \%$ ) pacientes murieron dentro de los primeros 30 días después de la cirugía. La tasa de éxito del procedimiento primario realizado en estos centros fue $94.9 \%$. Después de las reoperaciones la totalidad de los pacientes, menos 2 (99.5\%), fueron curados. La tasa global de curación, incluyendo los que tuvieron su operación primaria por fuera de los centros del estudio, fue $97.5 \%$.

\section{References}

1. Harrison, T.S., Child, C.G., Fry, W.J., Floyd, J.C., Fajans, S.S.: Current surgical management of functioning islet cell tumors of the pancreas. Ann. Surg. 178:485, 1973

2. van Heerden, J.A., Edis, A.J., Service, F.J.: The surgical aspects of insulinomas. Ann. Surg. 189:677, 1979

3. Le Quesne, L.P., Nabarro, J.D.N., Kurtz, A., Zweig, S.: The management of insulin tumors of the pancreas. Br. J. Surg. 66:373, 1979

4. Broughan, T.A., Leslie, J.D., Soto, J.M., Hermann, R.E.: Pancreatic islet cell tumors. Surgery 99:671, 1986

5. Galbut, D.L., Markowitz, A.M.: Insulinoma: Diagnosis, surgical management and long-term follow-up. Am. J. Surg. 139:682, 1980

6. Peiper, H.J.: Pankreatische Apudome. Chirurg 51:380, 1988

7. Howard, J.M., Moss, H., Rhoads, J.E.: Collective review: Hyperinsulinism and islet cell tumours of the pancreas. With 398 recorded tumours. Surg. Gynecol. Obstet. 90:417, 1950

8. Moss, N.H., Rhoads, J.E.: Islet Cell Tumors. Surgical Diseases of the Pancreas, Philadelphia, Lippincott, 1960

9. Filipi, C.J., Higgins, G.A.: Diagnosis and management of insulinoma. Am. J. Surg. 125:231, 1973

10. Stefanini, P., Carboni, M., Patrassi, N., Basoli, A.: Beta-islet cell tumors of the pancreas: Results of a study on 1067. Surgery 75:597, 1974

11. Kümmerle, F., Rückert, K.: Chirurgie des endokrinen Pankreas in der Bundesrepublik. Dtsch. Med. Wochenschr. 103:729, 1978

12. Boissel, P., Proye, C.: Les Tumeurs Endocrines du Pancréas, Paris, Masson, 1985

13. Whipple, A.O., Frantz, V.K.: Adenoma of the islet cell with hyperinsulinism. Ann. Surg. 101:1299, 1935

14. Daggett, P.R., Kurtz, A.B., Morris, D.V., Goodburn, E.A., Le 
Quesne, L.P., Nabarro, J.D.N., Raphael, M.J.: Is preoperative localisation of insulinomas necessary. Lancet 2:483, 1981

15. Grant, C.S., van Heerden, J.A., Charboneau, J.W., James, F.M., Reading, C.C.: Insulinoma: The value of intraoperative ultrasonography. Arch. Surg. 123:843, 1988

16. McMillan, F.L., Scheibe, J.R.: Islet cell tumor of the pancreas. Am. J. Surg. 82:759, 1951
17. Klotter, H.J., Rückert, K., Kümmerle, F., Rothmund, M.: The use of intraoperative sonography in endocrine tumors of the pancreas. World J. Surg. 11:635, 1987

18. Kennedy, T.: The management of the hypoglycemic patient. World J. Surg. 6:718, 1982

19. Rothmund, M., Rückert, K., Beyer, J.: Insulinome und seltene endokrine Pankreastumoren. Chirurg 57:541, 1986

\section{Invited Commentary}

\author{
Jeffrey A. Norton, M.D.
}

Surgical Metabolism Section, Surgery Branch, National Cancer Institute, National Institutes of Health, Bethesda, Maryland, U.S.A.

Insulinomas are the most common islet-cell tumor. If one excludes patients with Multiple Endocrine Neoplasia type I (MEN I) (these patients usually have multiple islet-cell tumors), insulinomas are generally benign $(90 \%)$, intrapancreatic (nearly $100 \%)$, and a solitary, small $(<2 \mathrm{~cm})$ neoplasm [1]. Surgical enucleation or resection has always been the treatment of choice and, if achieved, usually results in cure of the hypoglycemia. The major problems in management of patients with insulinoma are accurate diagnosis and tumor localization.

Rothmund and colleagues are to be commended for compiling a large, modern, multiinstitutional experience in the management of a curative, but potentially life-threatening, surgical condition-benign insulinoma. They report a large number of patients (396) and a very high cure rate (97.5\%). It is an honest, complete report as there is a considerable complication rate $(31.5 \%)$ and reoperation rate $(6.4 \%)$, but a very reasonable operative mortality rate $(2 \%)$. Therefore, the bottom-line message of this article is very good news. Experienced surgeons can cure the vast majority of patients with insulinoma with some morbidity, but acceptable mortality.

This commentary will analyze the information presented by the authors and attempt to envision future directions for possible improvement. One major point that the authors describe and appear to have convincingly demonstrated is the importance of accurate biochemical diagnosis. I agree that the diagnosis of insulinoma is made not by provocative tests, but by a standard 72-hour fast with simultaneous measurement of blood glucose and insulin levels. Factitious hypoglycemia can be ruled out by measurement of serum levels of antiinsulin antibodies, and plasma levels of C-peptide and proinsulin [2]. Increased plasma proinsulin immunoreactivity in the presence of elevated concentrations of insulin and C-peptide and symptoms from decreased levels of glucose form an unequivocal diagnosis of insulinoma. Patients with factitious hypoglycemia usually have low or absent plasma levels of C-peptide $(<660 \mathrm{pmol} / \mathrm{L})$, while patients with insulinoma usually have elevated levels $(>660$ $\mathrm{pmol} / \mathrm{L}$ ) [2]. The presence of high serum levels of antiinsulin antibodies are pathognomonic for the diagnosis of factitious hypoglycemia. With the increasing use of new preparations of recombinant human insulin, the diagnosis of factitious hypoglycemia may become more difficult and totally dependent on the detection of low plasma levels of $\mathrm{C}$-peptide and proinsulin in the presence of elevated circulating levels of insulin and hypoglycemia.

Another major point that Rothmund and associates stress is accurate preoperative localization of the islet-cell tumor. Noninvasive studies such as ultrasound, computed tomography, and even magnetic resonance imaging localize, at best, only $40 \%$ of insulinomas [3]. Invasive studies such as selective angiogram and transhepatic venous sampling (TVS) of the portal vein and its tributaries for insulin are much more likely to provide accurate localization. Selective angiography can precisely image approximately $60-80 \%$ of insulinomas and TVS can regionally localize nearly all tumors [3]. TVS localizes the islet-cell tumor to a region of the pancreas, head, body, or tail. The surgeon must intraoperatively determine the precise location of the tumor or resect the region based on an insulin gradient.

TVS may also be helpful in patients with Multiple Endocrine Neoplasia type 1. Pathological analyses of resected pancreatic specimens from these patients indicate that the glands nearly always have multiple islet-cell tumors [4]. As reported by Rothmund and colleagues, approximately $10 \%$ of patients with biochemical evidence of insulinoma will have multiple islet-cell tumors. It is my suspicion that each of these patients have MEN I. The presence of MEN I in patients with insulinoma should be carefully investigated preoperatively by careful history, by studies to detect the presence of other associated endocrine diseases, and, in the future, perhaps, by specific gene markers associated with MEN I [5]. In patients with MEN I, insulinoma, and the dilemma of multiple islet-cell tumors, TVS may suggest the specific portion of the pancreas to resect in order to remove the insulin secreting tumor and correct the hyperinsulinism and hypoglycemia [6].

In my opinion, an apparent deficiency in the report of Rothmund and associates is the lack of complete description and details about intraoperative localization and resection of insulinomas. There are 4 pieces of information stated in this article that may be construed to be consistent with the hypothesis that there was imprecise operative localization of islet-cell tumors in some patients. First, the authors stress the availability and use of intraoperative blood glucose monitoring. This study may be inexact and, at best, only provides indirect confirmatory evidence that the insulinoma has been removed. There have been false-negative and false-positive results reported with the use of intraoperative glucose monitoring [7] and it has been primarily advocated to assess the results of blind resections of part or all of the pancreas. Second, a large percentage $(10 \%)$ of patients with benign insulinomas in the head of the pancreas had Whipple pancreaticoduodenectomies to remove the tumor and some additional patients had total 